Inter-national Benchmarking of Road Safety: State of the Art Peer-reviewed author version

SHEN, Yongjun; HERMANS, Elke; BRIJS, Tom \& WETS, Geert (2013) Inter-national Benchmarking of Road Safety: State of the Art. In: The 16th International Conference Road Safety on Four Continents - Proceedings CD-ROM.

Handle: http://hdl.handle.net/1942/15149 


\title{
INTER-NATIONAL BENCHMARKING OF ROAD SAFETY: STATE OF THE ART
}

\author{
Yongjun Shen, Elke Hermans, Tom Brijs, and Geert Wets \\ Transportation Research Institute (IMOB) - Hasselt University \\ Wetenschapspark 5 bus 6, 3590 Diepenbeek, Belgium \\ E-mail: \{yongjun.shen, elke.hermans, tom.brijs, geert.wets\}@uhasselt.be
}

\begin{abstract}
The road traffic crashes and consequent injuries and fatalities, traditionally regarded as random, unavoidable 'accidents', have been more and more recognized as a preventable public health problem. Given the fact that more and more countries are taking steps to improve their road safety situation, there is a growing need for these countries to work together more closely, because there are quite a number of common problems that can be identified in close cooperation, and improvement can be expected by learning lessons from existing best practices in other countries. As a consequence, comparison between a range of countries in terms of their road safety performance and development or - using state-of-theart terminology - inter-national benchmarking of road safety, is currently widely advocated by most countries and international bodies. However, performing a successful road safety benchmarking practice is by no means easy. Challenges exist from the definition of benchmarking framework at the very beginning to the final decisions in terms of identification of best practices and establishment of a continuous process of mutual learning. In this paper, based on a brief review of the concept of benchmarking, a benchmarking cycle for road safety is proposed. Moreover, as a valuable benchmarking tool, the development of a road safety index is highlighted, a number of recent studies are presented, and some theoretical and practical issues are discussed.
\end{abstract}

\section{INTRODUCTION}

As one of the most fast growing sectors in the post-crisis socioeconomic context, transport systems are expected to experience an accelerated expansion in the next decades due to ever increasing population, rapid motorization, and rising incomes. However, rapid growth of traffic volume, especially motorized road mobility, has also resulted in continuously increasing safety problems, such as road crashes, premature deaths, as well as physical and psychological handicaps. In most regions of the world, especially for those low- and middleincome countries, this hidden epidemic is still spreading. As for the high-income countries, despite the fact that the number of road fatalities keeps decreasing over the last several decades, they also suffer from the road crash problem. The huge costs in health services and the added burden on public finances due to road traffic injuries and fatalities have also become increasingly socially unacceptable and difficult to justify to citizens. Under these circumstances, more and more countries are taking steps to improve their road safety situation. For instance, the United Nations proclaimed the period 2011 to 2020 as the 'Decade of Action for Road Safety' in May 2011, with the purpose of 50\% reduction in road fatalities and injuries on the predicted global death toll by 2020 (http://www.who.int/roadsafety/ decade_of_action/en/). However, countries work in most cases on their own to tackle their specific road safety problems. This is right to a large extent because the socioeconomic conditions, the motorization levels, and the road safety experiences are different from country to country and from region to region. However, for those countries within the same region or 
that have already passed through similar stages of challenges and development, there are quite a number of common problems that can be identified in a close cooperation, and improvement can be expected by learning lessons from existing best practices in other countries (even if the final solutions or priorities could be different from one country to another in accordance with their own safety characteristics). Consequently, comparison between a range of countries in terms of their road safety performance and development or - using state-of-the-art terminology - inter-national benchmarking of road safety, is currently widely encouraged and advocated by governments, donors, practitioners, planners, and researchers for the purpose of better understanding each country's relative safety situation, and moreover, trying to learn from those better-performing countries in terms of setting practical targets, designing effective strategies, determining intervention priorities, monitoring programme effectiveness, and ultimately, achieving its own safety objectives.

\section{THE CONCEPT OF BENCHMARKING}

The term benchmarking, originally derived from the work of cobblers who would place someone's foot on a 'bench' and mark it out to make the pattern for the shoes, was firstly invented in the private sector as a tool for improving various operations by establishing a point of reference by which it is possible to judge quality, value or other important factors. Now, the concept of benchmarking is further extended and widely adopted in both profit and non-profit organizations. One of the operational definitions of benchmarking is:

\section{"the process of continuously measuring and comparing ones business processes against comparable processes in leading organizations to obtain information that will help the organization identify and implement improvements." [American Productivity and Quality Center, 1993]}

First and foremost, benchmarking is a systematic comparison of the process and performance of one production entity against other entities, which could be countries, organizations, firms, industries, divisions, projects, or individuals. Moreover, the essence of benchmarking is the process of identifying the highest standard of excellence for products, services, or processes, and then making the improvements necessary to reach those standards - commonly known as 'best practice' [Bhutta and Huq, 1999]. In addition, benchmarking does not represent the end of the process, but is an ongoing diagnostic management tool focused on learning, collaboration and leadership to achieve continuous improvement in the organization over time [Garlick and Pryor, 2004].

In practice, benchmarking is a versatile tool that can be applied in a variety of ways to meet a range of requirements for improvement. It can firstly be used to make intraorganizational comparisons, which involves benchmarking against internal operations or standards, usually in a multidivision or multinational enterprise. Benchmarking can also be and most frequently is - used to make inter-organizational comparisons. It deals with benchmarking against other entities in the same context, no matter whether they are direct competitors or not. In addition, benchmarking can also be used to make longitudinal comparisons, where the performance of one or more production entities in different time periods is compared.

Since the first successful application implemented by Xerox Corporation in the late 1970s, benchmarking quickly became one of the fastest growing techniques for quality and performance improvement and has been receiving significant attention in a multitude of entities engaged in a variety of performance evaluation, quality management, and continuous improvement activities [Camp, 1989; Spendolini, 1992; Keehley et al., 1997; Srinivas, 2000; Lau et al., 2005; Luu et al., 2008; Lai et al., 2011]. 
In terms of road safety, more and more countries have recognized the importance of benchmarking practices in improving their level of road safety, especially the inter-national comparisons. Taking the European Union as an example, the European Commission has claimed that "the establishment of a structured and coherent cooperation framework which draws on best practices across the Member States, [i]s a necessary condition to implement in an effective manner the road safety policy orientations 2011-2020." [European Commission 2010]. An instructional definition on inter-national benchmarking of road safety is given as:

"a process in which countries evaluate various aspects of their performance in relation to other practices, among which the so-called 'best in class'. The benchmark results enable countries to learn from others as a basis for developing measures and programmes which are aimed at increasing their own performance." [Wegman and Oppe, 2010]

\section{BENCHMARKING PROCESS}

To implement benchmarking, a number of different process models have been proposed during the past decades describing the steps of a benchmarking study. One representative model is the benchmarking wheel [Andersen, 1995], which is shown in Figure 1.

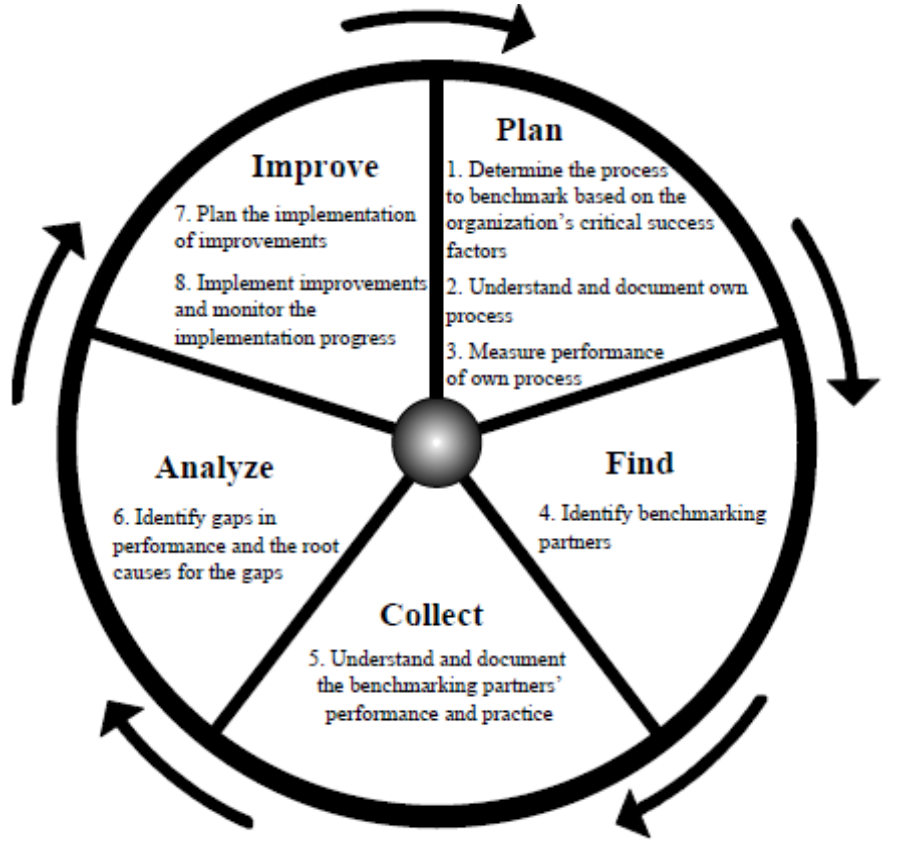

Figure 1: The benchmarking wheel (Source: Anderson, 1995)

The main content of each of the five phases in a typical benchmarking study is:

Phase 1 Plan. Prepare the benchmarking study by laying the groundwork for the coming phases, such as selecting the process to be benchmarked and thoroughly understanding how that process is performed within one's own organization.

Phase 2 Find. Identify benchmarking partners and obtain acceptance for their participation in the study.

Phase 3 Collect. Perform the same thorough documentation of the benchmarking partners' process as was done for one's own in the plan phase.

Phase 4 Analyze. Find gaps between the performance of one's own process and that of the benchmarking partners, and also determine the root causes for these gaps in practice.

Phase 5 Improve. Implement improvements based on the findings from the observation and analysis of the benchmarking partners. The outcomes can be used for the next benchmarking study with the purpose of continuous improvement. 
In the road safety context, a similar benchmarking cycle can be considered consisting of the following core activities (see Figure 2): determining the key components for road safety benchmarking, identifying the benchmarking partners (or countries), constructing indicators for meaningful comparisons and data gathering, examining gaps in performance and their root causes, and finally, establishing future attainable performance and monitoring progress. Each of these five activities poses different challenges for the benchmarking organization, and all of them are vital elements in a complete road safety benchmarking study.

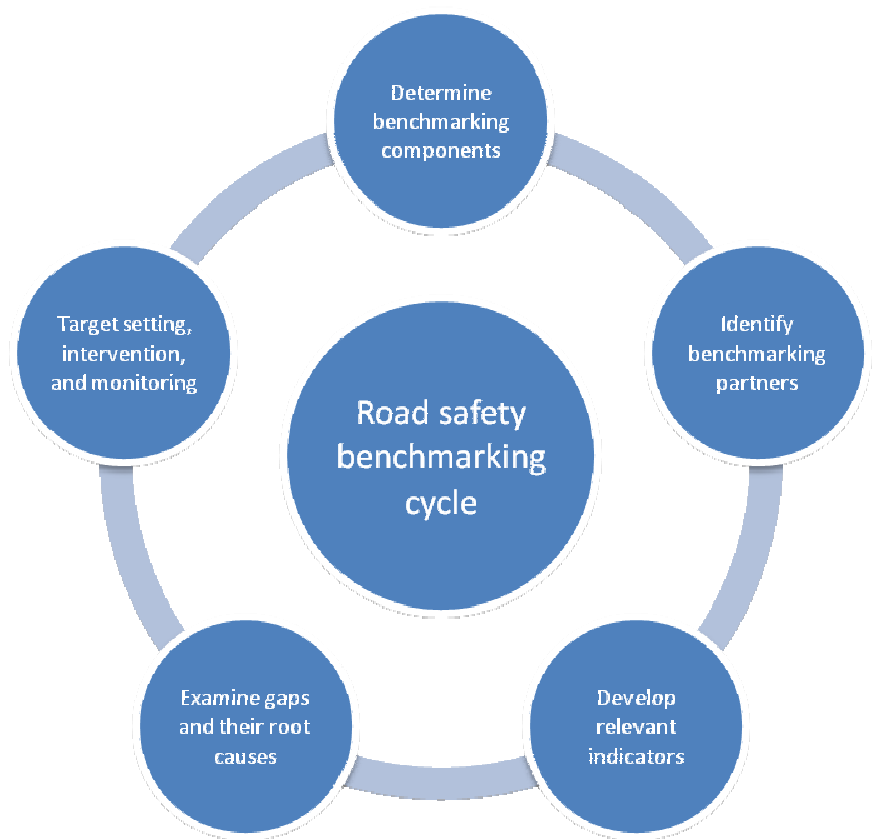

Figure 2: The road safety benchmarking cycle

\subsection{Determining the key components for road safety benchmarking}

To compare the road safety performance between countries, we should always determine what to benchmark in the first place. In this respect, Eksler (2009) proposed a so-called process and performance benchmarking framework for road safety management, which is presented in Figure 3.

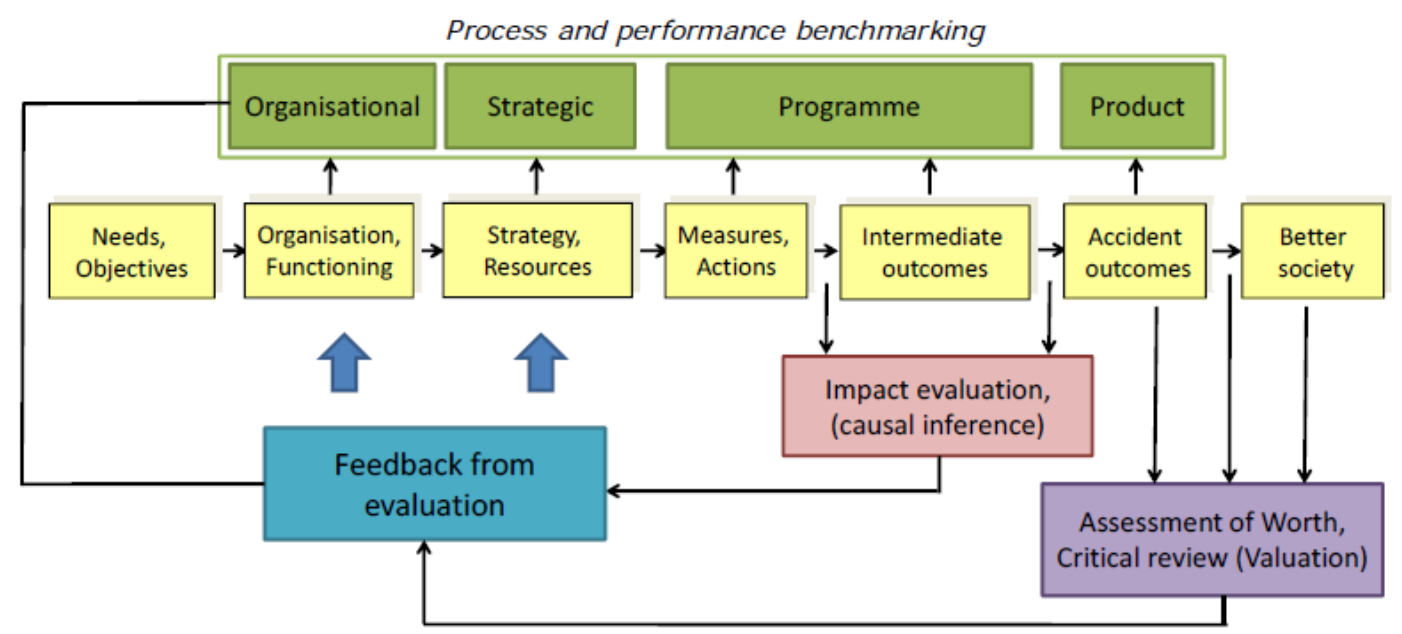

Figure 3: Process and performance benchmarking in road safety (Source: Eksler, 2009)

In this comprehensive benchmarking framework, four aspects of the road safety management and improvement process have been identified. They are: organization, strategy, programme and product. More specifically, product benchmarking is used to compare road 
safety final outcomes, such as road traffic mortalities. So far, most of the road safety benchmarking studies have focused on this aspect. Programme benchmarking, which is used to compare activities related to human-vehicle-infrastructure performance, such as drink driving, seat belt wearing, vehicle and road safety ratings, and corresponding policy action, has also been given more attention in current road safety studies since they are causally related to crashes or injuries and can provide a better understanding of the process that leads to crashes. Worldwide, the two most representative benchmarking studies concerning the above two aspects are the 'IRTAD Road Safety Annual Report' [International Traffic Safety Data and Analysis Group, 2012] and the 'Country Reports on Road Safety Performance' conducted within the OECD vision [OECD/ITF, 2008].

The remaining two aspects, i.e., strategic and organizational benchmarking, are used to compare national road safety strategies, resources, management and the organizational framework. However, due to the lack of appropriate indicators characterizing their features, only some initial attempts have been carried out at this moment, such as Al-Haji (2007), Wegman et al. (2008), and Eksler (2009).

In addition, Al-Haji (2007) and Wegman et al. (2008) also proposed the use of a road safety index, which combines performance indicators/indexes developed in the above separate benchmarking aspects into one overall index, and it is named as integrated benchmarking.

\subsection{Identifying the benchmarking partners}

Having determined the subject of the exercise, no matter if it is for road safety product benchmarking, programme benchmarking, or even for strategic and organizational benchmarking, the next step is to identify the benchmarking partners, i.e., with whom to compare.

It is, however, not an easy task to define an uniform criterion on the selection of benchmarking partners (or countries) for inter-national road safety benchmarking practices. In a general sense, all the countries are comparable in terms of their road safety performance. However, in order to achieve adequate and meaningful results during comparisons, road safety benchmarking studies usually have to be carried out between similar countries or regions at as much as possible the same level of development, motorization and with a similar type of transport system [Al-Haji, 2007]. For instance, in Europe, the SUNFlower study [Koornstra et al., 2002] focused on the three best-performing countries in road safety (Sweden, United Kingdom and the Netherlands) and in the following SUNFlower+6 study [Wegman et al., 2005], three Southern European countries (Greece, Portugal and Spain, with a special position for Catalonia) and three Central European countries (Hungary, Slovenia and the Czech Republic) were included; The SECBelt study [ETSC, 2005] worked on road safety causes and problems in the Southern, Eastern and Central European countries; Another ETSC study concentrated on the performances of Nordic countries (Denmark, Finland, Iceland, Norway and Sweden) in different areas of road safety [Eksler et al., 2009]. Moreover, some large-scale benchmarking studies were also carried out within the whole EU vision, such as the SafetyNet study [Thomas et al., 2009], the SUNFlowerNext study [Wegman et al., 2008], and the ongoing DaCoTA study (http://www.dacota-project.eu/).

\subsection{Constructing indicators for meaningful comparisons}

The third step for implementing inter-national benchmarking of road safety is to develop a set of relevant indicators for the selected benchmarking component. They can be measured in some common terms such as a rate (e.g., number of fatalities per population), a percentage (e.g., percentage of seat belt usage), or as qualitative information (e.g., level of national road safety intervention: 'low', 'relatively low', 'high', and 'extremely high'). Moreover, indicator values have to be collected for all the countries involved in the benchmarking study. In 
general, developing appropriate road safety indicators for a specific benchmarking study and structuring them in a logical way is the basis of a successful benchmarking practice.

Today, having recognized the complex character of the road safety phenomenon, a large number of road safety indicators have been developed and increasingly used as a supportive instrument for inter-national (or inter-regional) comparisons and monitoring of road safety progress (e.g., ETSC, 2001; Vis, 2005; Al-Haji, 2007; Wegman et al., 2008; Hermans, 2009; Gitelman et al., 2010, Shen, 2012).

Particularly, a road safety target hierarchy was proposed for the development of various indicators. The concept originated in New Zealand [Land Transport Safety Authority, 2000], and further used in the European SUNflower study [Koornstra et al., 2002] and the European SafetyNet study [Thomas et al., 2009] as well. Now, it has also become the theoretical basis for the creation of the European Road Safety Observatory with the purpose of bringing together all Community activities in relation to safety data and knowledge. In general, the target hierarchy describes road safety as a pyramid consisting of five vertical layers as presented in Figure 4.

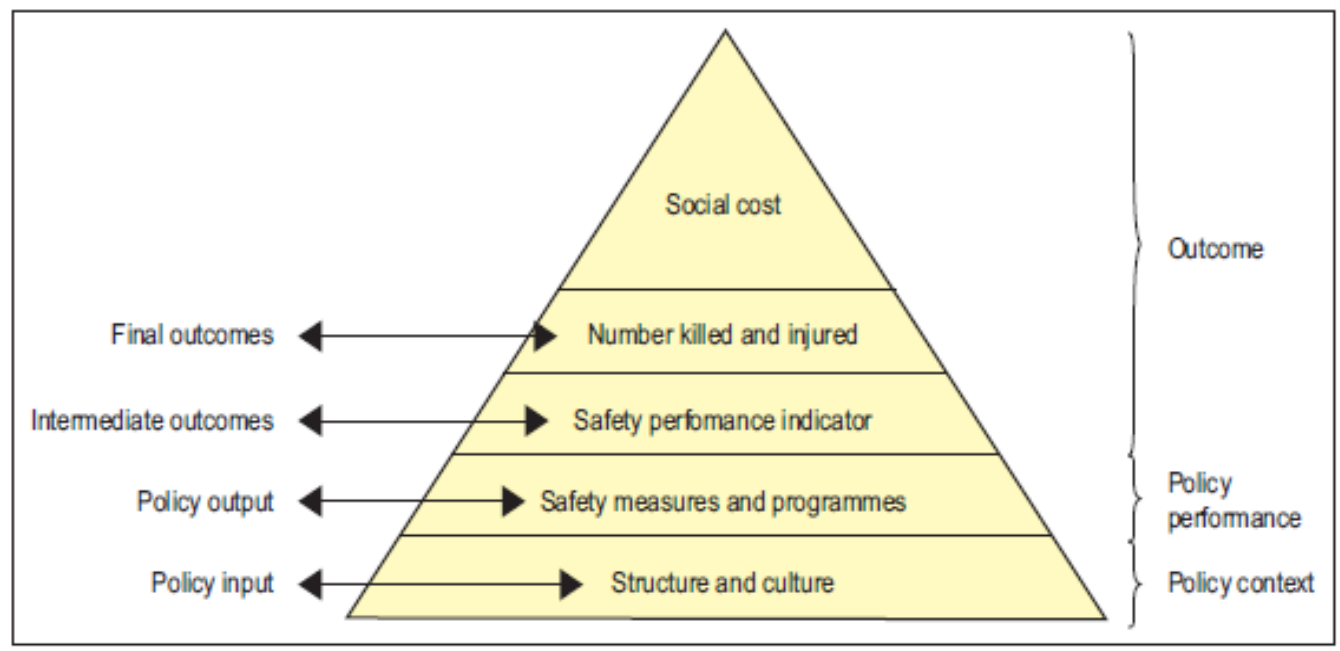

Figure 4: Target hierarchy for road safety (Source: Wegman et al., 2005)

From bottom to top they are: structure and culture (describing the background conditions of a country or its policy context); safety measures and programmes (or the road safety policy performance); safety performance indicators (also known as intermediate outcomes); the number of fatalities and casualties (as the final outcomes); and the social costs due to crashes and injuries at the very top.

The layers of the pyramid are stacked simply but logically. They imply the causal relationship between indicators at the different layers. For instance, policy interventions such as a high frequency of road side alcohol check, will first have to result in a decreasing rate on drinking and driving before it can be made credible that the intervention has an effect on reducing alcohol-related crashes and risks. In other words, the pyramid enables us to better understand the development at the top by explaining the change at the bottom.

\subsection{Examining gaps in performance and their root causes}

In this step, the process knowledge from the previous steps is put together to identify the gaps in road safety performance between the countries under study and to understand the root causes for these gaps. This is the most important step in the entire benchmarking study, but also the most challenging task to fulfill. Today, various benchmarking tools have been developed which range from relatively simple (e.g., using statistical tables and graphs) to highly complex (e.g., index-based approaches, see also Section 4), depending on the number of indicators involved, the details of data, and the complexity of techniques used in calculation and analysis. 
According to Camp (1995), an intuitive way for gap analysis is to present data in some graphical form. These graphics are easy to understand and are capable of illustrating multiple dimensions simultaneously. However, it is a difficult task for the analysts to integrate all the elements into complete and meaningful information. Ratio analysis [Schefcyzk, 1993] is another approach that is commonly used due to its simplicity, such as using the number of fatalities per population to rank countries in a road safety product benchmarking study. One problem with ratios is that there can be several of them (e.g., the number of fatalities per vehicles and the number of fatalities per distance travelled). Comparisons of a single ratio might thereby lead to misclassifications and incorrect judgments. In the applications of multiple ratios, the weighting of the ratios would require the formulation of complex decision rules and their justification, as well as a much greater computational workload. An available solution is to perform multi-criteria decision analysis, and one of the methods belonging to this category is known as analytic hierarchy process (AHP) [Saaty, 1980], which utilizes a weighted scoring method in the analysis of various indicators. It provides a single score using perceptual values as set forth by decision makers. Despite being effective, the main drawback of this method is the involvement of a high degree of subjectivity.

The ordinary least squares (OLS) statistical techniques, such as multiple regression, are also widely applied to assess comparative performance of different entities [Hayashi, 2000]. Even though there is a strong theoretical foundation for such statistical tools, their primary limitation is in the underlying assumptions of normality, homoscedasticity, and serial independence of regression residuals. Also, Bessent et al. (1982) indicate that major difficulties arise when the OLS is used in multiple output cases due to the implicit impact on outputs having the same input resources. In addition, it measures a correlation or central tendency rather than best practice.

Frontier analysis is one other technique recently receiving significant attention in benchmarking studies. The data envelopment analysis (DEA) and the stochastic frontier approach (SFA) are the two representatives within this field [Coelli et al., 2005; Bogetoft and Otto, 2011]. The SFA uses statistical techniques to estimate a transformation frontier and to estimate efficiency relative to the estimated stochastic frontier [Aigner et al., 1977]. A valuable characteristic of this approach is the introduction of a disturbance term representing noise, measurement error and exogenous shocks beyond the control of the production unit. This phenomenon permits decomposition of the deviation of an observation from the deterministic kernel of the frontier into two components: inefficiency and noise. On the other hand, the method imposes an a priori assumption on the production technology by choosing a functional form (e.g., Cobb-Douglas, translog, etc.), which is risky because most of the distributional characteristics of the production technology are a priori unknown. Moreover, the precise specification of the error structure is difficult, sometimes even impossible to ascertain. Such specification is in fact likely to introduce another potential source of error. Compared with the stochastic parametric frontier approach, the DEA is a non-parametric method imposing no assumptions on the specific statistical distribution of the error terms. It applies mathematical programming methodology to measure the relative efficiency of a homogeneous set of decision making units (DMUs) by constructing an efficient production frontier based on best practice(s) [Charnes et al., 1978]. In doing so, the data are believed to be able to 'speak for themselves' and the specification error is minimized. However, the DEA model does not allow for measurement error or random shocks. Instead, all these factors are attributed to calculate (in)efficiency.

\subsection{Establishing future attainable performance and monitoring progress}

After finishing the analysis, this step performs target-setting for those underperforming countries in terms of different road safety aspects, and also determines what needs to be done 
to match the best practice and to fill the gaps for the process. Moreover, as a cycle, such a benchmarking practice should be carried out at regular intervals so as to evaluate the results of interventions and to monitor progress on road safety in each country in order to achieve continuous improvement over time.

\section{A BENCHMARKING TOOL: ROAD SAFETY INDEXES}

As indicated in the previous section, to be able to implement inter-national benchmarking in the field of road safety, a set of indicators that summarizes the country's road safety performance from different benchmarking aspects has to be developed, which serves as the basis for a successful benchmarking process. However, when a number of indicators are considered for a particular benchmarking aspect, simple comparisons per indicator with the purpose of examining the gaps in performance may only show a small piece of the road safety picture, and can be misleading since different countries may operate in different circumstances with different focal points. Consequently, a composite road safety indicator (or index), which combines individual indicator values into one single score, is often computed for the sake of meaningful benchmarking.

Different from separate indicators, a composite indicator or index $(\mathrm{CI})$ is a mathematical aggregation of a set of individual indicators that measures multi-dimensional concepts but usually has no common units of measurement [Saisana and Tarantola, 2002]. During the last decade, a large number of CIs have been developed by various national and international organizations, such as the Human Development Index, the Environmental Sustainability Index, the Overall Health System Achievement Index, and so on [Saisana and Tarantola, 2002; Munda, 2005; OECD, 2008; Bandura, 2008].

Compared to other research fields, the development of a composite index for road safety benchmarking is relatively new, since the traditional studies mainly focus on the road safety final outcomes, and ratio analysis is commonly conducted, such as using the number of fatalities per head of population to assess the relative road safety situation of a country. Nowadays, since more and more indicators are developed describing the complex character of the road safety phenomenon, simple ratio analysis no longer satisfies the need of modern road safety benchmarking practices. Recently, several studies were carried out aiming at the development of a composite road safety index which enabled meaningful national or subnational comparison and monitoring of road safety performance.

Specifically, Al-Haji (2007) suggested a road safety development index (RSDI) which consists of three focus themes of the road safety domain. They were product focus (fatality rates), people focus (road user behaviour), and system focus (safer vehicles, safer roads, socio-economic level, enforcement, and organizational performance). The index was then applied for the comparison of road safety progress in highly motorized countries (eight European countries) on the one hand and less motorized countries (five Southeast Asian countries) on the other hand. Although different numbers of road safety indicators were selected representing the above three focuses in each empirical study due to data availability, one composite index was expected for both sub-studies. For this purpose, four weighting methods were adopted, which were equal weighting, expert judgments, subjective weights based on previous experience, and principal component analysis. The empirical and theoretical assessments indicated that the proposed RSDI could give a broader picture of the road safety situation in a country than single indicators and could serve as a simple and easily understandable tool for policy makers and the public.

Hermans et al. (2008) explored a methodological framework for developing a composite road safety performance index for cross-country comparison. The following steps were distinguished: selecting indicators, collecting indicator data, univariate analysis, multivariate analysis, weighting, aggregation, robustness testing, and computing, evaluating and 
visualizing final index scores. To illustrate the use of this framework, six risk factors, i.e., alcohol and drugs, speed, protective systems, vehicle, roads, and trauma management, were considered, one safety performance indicator for each risk factor was defined, and five weighting approaches were investigated to combine the separate indicators into one overall index for 21 European countries, which were: factor analysis, budget allocation, analytic hierarchy process, data envelopment analysis, and equal weighting. The results were further compared with one of the road safety risk indicators, which was the number of fatalities per million inhabitants. The study concluded that comparing the performance of countries in terms of road safety by means of an index at the intermediate outcome level enabled earlier and goal-oriented action.

Furthermore, in the SUNflowerNext study [Wegman et al., 2008, Gitelman et al., 2010], three different types of performance indicators were distinguished, which were road safety performance indicators (i.e., the top three layers of the pyramid in Figure 4), implementation performance indicators (dealing with different components of causal relationships between the different layers of the pyramid, such as between the changes in safety performance indicators and changes in the number of casualties), and policy performance indicators (i.e., the second layer of the pyramid from the bottom). Moreover, a composite road safety index combining the indicators in each layer of the pyramid was explored. Two weighting schemes, i.e., principal component analysis and factor analysis, were examined based on the data collected for 27 European countries. The analysis revealed that such an index gave a more enriched picture of road safety and the countries' ranking based on the combination of different indicators was not necessarily similar to the traditional ranking of countries based only on mortality or fatality rates.

Recently, Shen (2012) carried out research regarding the combination of risk indicators on the one hand and a hierarchy of safety performance indicators on the other hand for the sake of meaningful road safety benchmarking of 28 European countries. Based on the identification of six leading road safety risk factors (i.e., alcohol, speed, protective systems, vehicle, road, and emergency medical services) within the three main road transport components (i.e., road user, vehicle, and infrastructure), a comprehensive set of hierarchically structured safety performance indicators was developed to capture the road safety performance of a country. The technique of data envelopment analysis and its various extensions were investigated to develop a composite road safety performance index for crosscountry comparison. In doing so, the hierarchical structure of the indicators was taken into account, and some practical challenges related to data (including missing values and qualitative indicators) were explored. The constructed road safety performance index showed a high correlation with the overall road safety risk from the view of the final outcome level, and useful insight in the areas of underperformance in each country was gained.

All the studies mentioned above clearly demonstrate the necessity and feasibility of creating a composite road safety index for road safety benchmarking purposes. In doing so, however, an appropriate selection of road safety indicators, a harmonized data collection procedure, and a scientifically sound methodology are the fundamental conditions of making meaningful comparisons between countries, and also the key to designing more effective safety policies.

\section{DISCUSSION AND CONCLUSION}

Road safety is an important policy area that can benefit from the implementation of various inter-national benchmarking practices. It is therefore widely advocated by most countries and international bodies nowadays. However, performing a successful road safety benchmarking practice is by no means easy. Challenges exist from the definition of benchmarking framework at the very beginning to the final decisions in terms of identification of best 
practices and establishment of a continuous process of mutual learning. For instance, integrated benchmarking was implemented in some studies which combined indicators in all the different benchmarking aspects (i.e., product benchmarking, programme benchmarking, strategic benchmarking, and also organizational benchmarking) in one road safety index. The idea itself is attractive, however, it is well accepted and proved that underlying causal relationships exist between different benchmarking components. Integrating all these components thereby implies to combine indicators that are actually inter-dependent, which is not in accordance with the basic principle of index construction and will generate a problem of double or even triple counting the effect of one factor in the final index. This obstacle restricts to a great extent the application of this concept unless a new theoretical framework appears. Considering each benchmarking aspect separately, most of the current road safety product benchmarking practices focus entirely on fatalities, which however, represent only the 'tip of the iceberg' of the road crash problem and could lead up to an overestimation of this aspect. International cooperation in terms of non-fatal injury data collection and harmonization is therefore sorely required, which will be beneficial to all bodies that are concerned with road safety management. With respect to the road safety programme benchmarking, an appropriate selection of the risk factors (e.g., speed) and the corresponding performance indicators, as well as the collection of reliable and comparable indicator data, are still lacking to a certain extent, which therefore call for different kinds of development efforts relating to concepts, methodologies, and data collection procedures. Furthermore, by collecting the safety performance data at regular intervals, systematic country comparison over time should be conducted so as to evaluate the results of policy interventions and to monitor the progress in road safety performance. In addition to the road safety product and programme benchmarking, other aspects of the road safety management and improvement process, such as road safety strategic and organizational benchmarking are also desirable to be implemented, and the interrelation between different benchmarking practices should be studied in detail.

In short, inter-national benchmarking of road safety performance and development has and will continue to play an important role in improving a country's road safety level. All the five core activities proposed in this paper, i.e., determining the key components for road safety benchmarking, identifying the benchmarking partners, constructing indicators for meaningful comparisons and data gathering, examining gaps in performance and their root causes, and establishing future attainable performance and monitoring progress, are therefore crucial for a successful road safety benchmarking practice, and need to be carefully planed, designed, and implemented. Moreover, from the road safety policy point of view, we should always keep in mind that benchmarking does not represent the end of the process, but is an ongoing diagnostic management tool requiring effective strategies, sufficient allocation of resources, successful implementation, and persistent monitoring and evaluation in order to achieve continuous improvement over time.

\section{REFERENCES}

Aigner, D.J., Lovell, C.A.K. \& Schmidt, P., (1977). Formulation and estimation of stochastic frontier production functions, Journal of Econometrics, Vol. 6, pp. 21-37.

Al-Haji, G., (2007). Road Safety Development Index (RSDI): Theory, Philosophy and Practice. Department of Science and Technology. PhD Dissertation, Campus Norrköping, Linköping University, Norrköping.

American Productivity and Quality Center, (1993). The Benchmarking Management Guide, Productivity Press, Inc., Portland.

Andersen, B., (1995), The Results of Benchmarking and a Benchmarking Process Model, Ph.D. Dissertation, Norwegian Institute of Technology, Trondheim, Berlin. 
Bandura, R., (2008). A Survey of Composite Indices Measuring Country Performance: 2008 Update, United Nations Development Programme - Office of Development Studies.

Bessent, A., Bessent, W., Kennington, J. \& Reagan, B., (1982). An application of mathematical programming to assess productivity in the Houston independent school district, Management Science, Vol. 28, No. 2, pp. 82-107.

Bogetoft, P. \& Otto, L., (2011). Benchmarking with DEA, SFA, and R, International Series in Operations Research \& Management Science, Vol. 157, Springer.

Bhutta, K.S. \& Huq, F., (1999). Benchmarking-Best practices: An integrated approach, Benchmarking: An International Journal, Vol. 6 No. 3, pp. 254-268.

Camp, R.C., (1989). Benchmarking: The Search for Industry Best Practices that Lead to Superior Performance, ASQ Quality Press, Milwaukee.

Camp, R.C., (1995). Business Process Benchmarking: Finding and Implementing Best Practices, ASQ Quality Press, Milwaukee.

Charnes, A., Cooper, W.W. \& Rhodes, E., (1978). Measuring the efficiency of decision making units, European Journal of Operational Research, Vol. 2, pp. 429-444.

Coelli, T.J., Rao, D.S.P., O'Donnell, C.J. \& Battese, G.E., (2005). An Introduction to Efficiency and Productivity Analysis, 2nd Edition. Springer.

Eksler, V., (2009). Road Mortality in Europe: A Regional Approach, PhD dissertation, UVSQ, Saint-Quentin-en-Yvelines.

Eksler, V., Popolizio, M., \& Allsop, R., (2009). How far from Zero? Benchmarking of Road Safety Performance in the Nordic Countries, European Transport Safety Council, Brussels.

European Commission (EC), (2010). Towards a European Road Safety Area: Policy Orientations on Road Safety 2011-2020. COM (2010) 389 final, Commission of the European Communities, Brussels.

European Transport Safety Council (ETSC), (2001). Transport Safety Performance Indicators, ETSC, Brussels.

European Transport Safety Council (ETSC), (2005). SECBelt Report: The Safety of Vulnerable Road Users in the Southern, Eastern and Central European Countries, ETSC, Brussels.

Gitelman, V., Doveh, E. \& Hakkert, S., (2010). Designing a composite indicator for road safety, Safety Science, Vol. 48, pp. 1212-1224.

Hayashi, F., (2000). Econometrics, Princeton University Press, Princeton.

Hermans, E., Van den Bossche, F. \& Wets, G., (2008). Combining road safety information in a performance index, Accident Analysis and Prevention, Vol. 40, No. 4, pp. 1337-1344.

Hermans, E., (2009). A Methodology for Developing a Composite Road Safety Performance Index for Cross-country Comparison, PhD dissertation, Hasselt University, Hasselt.

International Traffic Safety Data and Analysis Group, (2012). IRTAD Road Safety Annual Report 2011, Organization for Economic Co-operation and Development/International Transport Forum, Paris. www.irtad.net.

Keehley, P., Medlin, S., MacBride, S. \& Longmire, L., (1997). Benchmarking for Best Practices in the Public Sector, Jossey Bass, California.

Koornstra, M., Lynam, D., Nilsson, G., Noordzij, P., Petterson, H-E., Wegman, F., Wouters, P., (2002). SUNflower: A Comparative Study of the Development of Road Safety in Sweden, the United Kingdom, and the Netherlands. SWOV Institute for Road Safety Research, Leidschendam.

Lai, M., Huang, H. \& Wang, W., (2011). Designing a knowledge-based system for benchmarking: A DEA approach, Knowledge-Based Systems, Vol. 24, pp. 662-671.

Land Transport Safety Authority (LTSA), (2000). Road Safety Strategy 2010; A Consultation Document, National Road Safety Committee, LTSA, Wellington. http://www.ltsa.govt.nz/ publications/rs-framework.html. 
Lau, H.C.W., Lau, P.K.H., Fung, R.Y.K., Chan, F.T.S. \& Ip, R.W.L., (2005). A virtual case benchmarking scheme for vendors' performance assessment, Benchmarking: An International Journal, Vol. 12, No. 1, pp. 61-80.

Luu, V., Kim, S. \& Huynh, T., (2008). Improving project management performance of large contractors using benchmarking approach, International Journal of Project Management, Vol. 26, No. 7, pp. 758-769.

Munda, G., (2005). Multi-Criteria Decision Analysis and Sustainable Development, In: Figueira, J., Greco, S. \& Ehrgott, M. (Eds.), Multiple-Criteria Decision Analysis: State of the Art Surveys, Springer International Series in Operations Research and Management Science, New York, pp. 953-986.

Organization for Economic Co-operation and Development (OECD), (2008). Handbook on Constructing Composite Indicators: Methodology and User Guide, OECD, Paris. www.oecd.org/publishing/corrigenda.

Organization for Economic Co-operation and Development/International Transport Forum (OECD/ITF), (2008). Country Reports on Road Safety Performance, Joint Transport Research Centre of the OECD and the ITF, Paris.

Saaty, T.L., (1980). The Analytic Hierarchy Process, McGraw-Hill, New York.

Saisana, M., \& Tarantola, S., (2002). State-of-the-Art Report on Current Methodologies and Practices for Composite Indicator Development, EUR 20408 EN Report, the Joint Research Center of European Commission, Ispra.

Schefcyzk, M., (1993). Industrial benchmarking: A case study of performance analysis techniques. International Journal of Production Economics, Vol. 32, No. 1, pp. 1-11.

Shen, Y., (2012). Inter-national Benchmarking of Road Safety Performance and Development using Indicators and Indexes: Data Envelopment Analysis based Approaches. PhD dissertation, Hasselt University, Hasselt.

Spendolini, M., (1992). The Benchmarking Book, American Management Association, New York.

Srinivas, T. (2000). A benchmarking method for business-process reengineering and improvement, The International Journal of Flexible Manufacturing Systems, Vol. 12, pp. 291-304.

Thomas, P., Yannis, G., Duchamp, G., Vis, M., Jahi, H., Vallet, G. \& Dupont, E., (2009). SafetyNet Final Activity Report, the EU FP6 project SafetyNet.

Vis, M.A. (Ed.), (2005). State of the Art Report on Road Safety Performance Indicators, Deliverable D3.1 of the EU FP6 project SafetyNet.

Wegman, F., Commandeur, J., Doveh, E., Eksler, V., Gitelman, V., Hakkert, S., Lynam, D. \& Oppe, S., (2008). SUNflowerNext: Towards a Composite Road Safety Performance Index, Deliverable D6.16 of the EU FP6 project SafetyNet.

Wegman, F., Eksler, V., Hayes, S., Lynam, D., Morsink, P. \& Oppe, S., (2005). SUNflower+6: A Comparative Study of the Development of Road Safety in the SUNflower+6 Countries: Final Report. SWOV Institute for Road Safety Research, Leidschendam.

Wegman, F. \& Oppe, S., (2010). Benchmarking road safety performances of countries, Safety Science, Vol. 48, pp. 1203-1211. 